\title{
Road effects on bat activity depend on surrounding habitat type
}

\author{
Denis Medinas a,b,*, Vera Ribeiro ${ }^{\mathrm{a}, \mathrm{b}}$, João Tiago Marques ${ }^{\mathrm{a}, \mathrm{b}}$, Bruno Silva ${ }^{\mathrm{b}}$, Ana Márcia Barbosa ${ }^{\mathrm{b}}$, \\ Hugo Rebelo ${ }^{\mathrm{c}, \mathrm{d}, \mathrm{e}}$, António Mira ${ }^{\mathrm{a}, \mathrm{b}}$ \\ a Conservation Biology Unit, Department of Biology, University of Évora, Pólo da Mitra, 7002-554 Évora, Portugal \\ b CIBIO/InBIO-UE, Research Centre in Biodiversity and Genetic Resources, University of Évora, Rua Dr. Joaquim Henrique da Fonseca, 2nd, 7002-554 Évora, Portugal \\ c CIBIO/InBIO-UP, Research Centre in Biodiversity and Genetic Resources, University of Porto, Rua Padre Armando Quintas, 4485-661 Vairão, Portugal \\ ' CEABN-InBIO, Centre for Applied Ecology "Prof. Baeta Neves", Institute of Agronomy, University of Lisbon, Tapada da Ajuda, 1349-017 Lisbon, Portugal \\ e School of Biological Sciences, University of Bristol, Woodland Road, Bristol, BS8 1UG Bristol, UK
}

\section{H I G H L I G H T S}

- Low-medium traffic roads have a major negative impact on bat activity.

- Road-effect zone is guild-specific and depends on the surrounding habitat.

- Negative effects extend to about $300 \mathrm{~m}$ from the roads in woodland and $>500 \mathrm{~m}$ in open field habitat.

- High-suitable habitats buffer the negative effects of roads.

- Road verges may provide resources for bats in lower-suitable habitat.

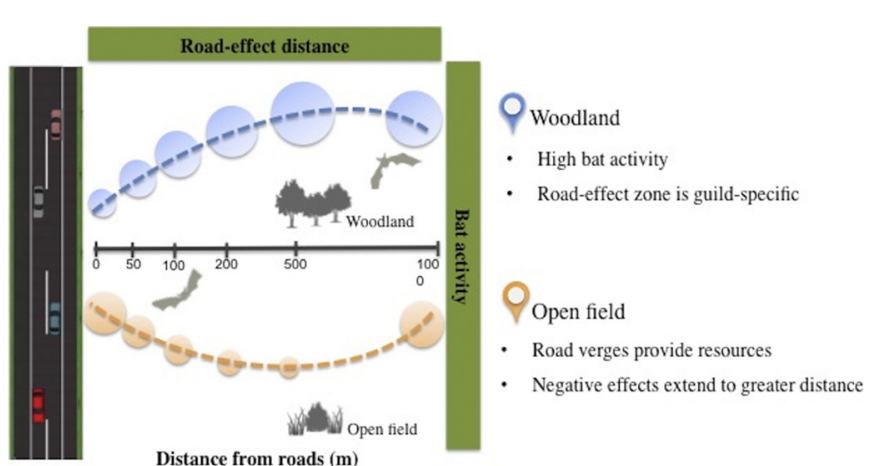

G R A P H I C A L A B S T R A C T

Distance from roads (m)

\section{A R T I C L E I N F O}

\section{Article history:}

Received 21 October 2018

Received in revised form 4 January 2019

Accepted 4 January 2019

Available online 06 January 2019

Editor: Damia Barcelo

\section{Keywords:}

Road-effect zone

Bat guilds activity

Low-medium traffic roads

Road-surrounding habitat

Roads verges

\footnotetext{
* Corresponding author at: Conservation Biology Unit, Department of Biology, University of Évora, Pólo da Mitra, $7002-554$ Évora, Portugal.

E-mail addresses: denism@uevora.pt (D. Medinas), hugo.rebelo@cibio.up.pt (H. Rebelo), amira@uevora.pt (A. Mira).
} 
management of roadside vegetation, combined with the bat habitat improvement in areas that are further from the roads, may mitigate the negative effects. To make road-dominated landscapes safer for bats, the transport agencies need to balance the trade-offs between habitat management and road kill risk.

(C) 2019 Elsevier B.V. All rights reserved.

\section{Introduction}

Roads are widespread features of many countries, and they form dense worldwide networks, such that there are few road-free areas remaining. In Europe, at least a quarter of the continent's surface is located within $500 \mathrm{~m}$ of the nearest transport infrastructure (Torres et al., 2016). The road network strongly contributes to landscape fragmentation or degradation by dissecting continuous areas that have high conservation values, and this fragmentation is considered to be a major driver for negative impacts on natural worldwide populations (Fahrig and Rytwinski, 2009; Forman et al., 2003; Grilo et al., 2012; Jaeger et al., 2005). The most perceptible of such impacts is wildlife-vehicle collisions. However, the combination of road avoidance and road barrier effects may contribute to reduced gene flow between roadside populations. Roads also decrease the suitability of adjacent habitats, by altering the physical (e.g., noise and light) and chemical environments. These changes will likely increase the risk of local extinctions (Ascensão et al., 2016; Jackson and Fahrig, 2011; Reed et al., 2007; Westemeier, 1998). Additionally, these negative effects are usually cumulative in the long-term (Balkenhol and Waits, 2009) and can extend their influence to distances of several hundred metres away from roads and into the habitat matrix (e.g., road-effect zone) (Forman et al., 2003). The spatial extension of the impacts of roads on surrounding areas has been studied for many species and can range from $<100 \mathrm{~m}$ to over $5000 \mathrm{~m}$, depending on the road type, the crossed habitat and the traits of the species (BenítezLópez et al., 2010; Bennett et al., 2013; Rotholz and Mandelik, 2013). Currently, most of the studies of road effects on biodiversity focus on hightraffic transport infrastructures, highways and motorways. However, approximately $50 \%$ of worldwide roads are low- and medium-traffic roads. Thus, it is surprising that for these types of roads, which comprise the majority of the world's roads, information about their potential impacts on wildlife is still lacking (Clevenger and Waltho, 2000; Dodd et al., 2004; Yanes et al., 1995).

However, roads may also attract wildlife, as they provide a favourable habitat along roadside verges (e.g., shelter and/or movement corridors for a large number of taxa - Davies and Pullin, 2007; Penone et al., 2012) and provide foraging opportunities (e.g., carrion for scavengers - Santos et al., 2016). For some of these species, roads and their verges can become ecological traps because the attracted individuals have a higher risk of becoming road kill (Bernes et al., 2017). Several studies support that the role of roadside verges, either as detractors or attractants, may depend on the surrounding landscape. O'Farrell and Milton (2006) demonstrated that, when crossing high-quality habitats, road verges do not provide habitats for several threatened shrew species. Similarly, Galantinho et al. (2017) found no effects on the density and survival of a forest-dwelling small mammal species (Apodemus sylvaticus) when comparing roadside verges and roadless areas in a Mediterranean forest area, which is a high-quality habitat for this species. Conversely, in intensive agricultural landscapes, roadside verges are often the only remnants of semi-natural habitats and have an important role as corridors or refuges of biodiversity (Penone et al., 2012; de Redon et al., 2015).

A primary concern for biodiversity conservation is to understand the extent to which roads affect the persistence and population of each species (Forman and Alexander, 1998). Rytwinski and Fahrig (2013) showed that species with slow life histories and large home ranges can be particularly affected by roads. For example, bats have very low reproductive rates, can have long lives and need large areas for foraging. Thus, transport infrastructures are likely to induce significant negative impacts on this group of mammals.
Several studies have shown that bats suffer frequent road kills (Gaisler et al., 2009; Lesiński, 2007; Lesiński et al., 2010; Medinas et al., 2013; Russell et al., 2009; Secco et al., 2017), have reduced foraging activity near roads with street lighting (Hale et al., 2015; Stone et al., 2009; Stone et al., 2012) or intense traffic noise (Luo et al., 2015; Schaub et al., 2008; Siemers and Schaub, 2011) and have restricted access to some habitats when these areas are dissected by roads (i.e., barrier effect) (Kerth and Melber, 2009). Other studies have shown that gleaning species are less active and that species richness decreases, when approaching the major roads (Zurcher et al., 2010; Berthinussen and Altringham, 2012; Kitzes and Merenlender, 2014). In a study on railways, Vandevelde et al. (2014) showed that the commuting activity of aerial hawking bats is higher over verges than in the surrounding intensive agricultural habitat. However, because of the very low train traffic at night and the narrow railway corridors, the negative effects of these infrastructures on bats are potentially weaker than those of roads. Thus, bats may show contrasting behaviours, in regard to transport infrastructures, depending on their type, features and surrounding habitats. Their response is also likely to be dependent on the functional groups of the bats (hereafter called guilds).

We investigated the effect of distance to low-medium traffic roads, as well as the importance of road-surrounding habitats, on bat activity patterns in a Mediterranean landscape. It was assumed that bats reduce their activity even in proximity to low-medium traffic roads. We also hypothesized that the characteristics of the surrounding habitats would modulate the road-effect zone, with this zone this being larger in open agricultural areas, when compared with woodlands. Moreover, the road-effect zone should also be guild specific. Short- (SRE) and mid-range (MRE) echolocators, which are more adapted to fly in woodland and vegetated edges (Frey-Ehrenbold et al., 2013), would avoid roads that cross woodlands, but could use vegetated verges of roads that are imbibed in open areas. Additionally, the long-range echolocators (LRE) bats, which generally forage in wide-open spaces, as well as above the tree canopy level, should be less affected. To test these hypotheses, we identified the road-effect zone for the overall bat community, SRE, MRE and LRE bats, as well as for Pipistrellus kuhlii (the most common bat species). We also evaluated whether the road-surrounding habitats (woodlands or open agricultural field) had an effect on the road-effect zone.

\section{Methods}

\subsection{Study area and sampling design}

This study was conducted in southern Portugal $\left(38^{\circ} 32^{\prime} 24^{\prime \prime}\right.$ to $38^{\circ} 47^{\prime}$ $33^{\prime \prime} \mathrm{N} ;-08^{\circ} 13^{\prime} 33^{\prime \prime}$ to $-07^{\circ} 55^{\prime} 45^{\prime \prime} \mathrm{W}$ ) within a landscape dominated by cork (Quercus suber) and holm oak (Quercus rotundifolia) savannah-like woodlands (the Portuguese "montado"), which alternated with arable fields, olive groves and vineyards (Fig. 1). The climate is Mediterranean, with the mean temperature ranging from $5.8^{\circ} \mathrm{C}$ to $12.8^{\circ} \mathrm{C}$ in the winter season (January), and from $16.3^{\circ} \mathrm{C}$ to $30.2{ }^{\circ} \mathrm{C}$ in the summer season (July), as well as an annual rainfall averaging $609.4 \mathrm{~mm}$ (Évora 1971-2000; Instituto de Metereologia, 2010). The terrain is flat to gently undulating and ranges from $150 \mathrm{~m}$ to $400 \mathrm{~m}$ above sea level.

We conducted point-count surveys along 20 transects, with bat activity recorded at each of six point-locations along each transect at 0 , 50, 100, 200, 500 and $1000 \mathrm{~m}$ (Fig. 1) approximately perpendicular to three national roads (EN4, EN114 and EN370) and one municipal road (M529). These roads are single-carriageway roads with an average night traffic of 277 to 1210 vehicles/night (EN114 and EN4, 


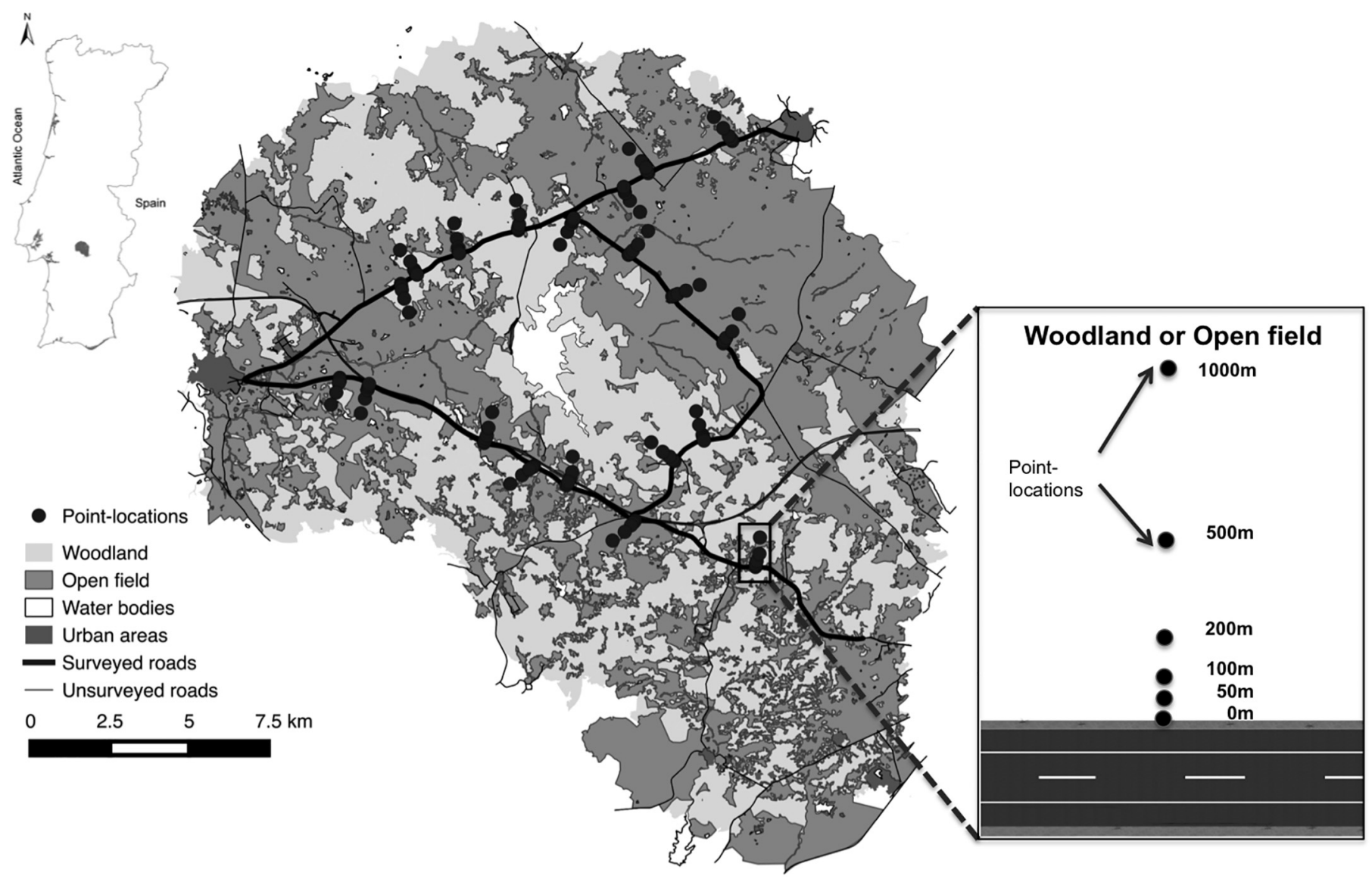

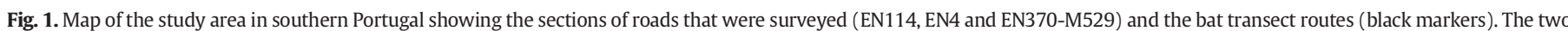

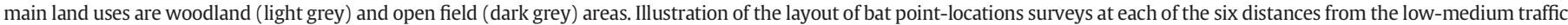
roads.

respectively) and an average night traffic of $<100$ vehicles/night (EN370 and M529). Following the classification of the Portuguese Road Institute, these data were grouped into three nocturnal traffic categories: medium-high traffic for EN114 (1210 vehicles/night), medium traffic for N4 (277 vehicles/night) and low traffic for EN370 and M529 (both with $<100$ vehicles night), with the low traffic roads hereafter referred to together as EN370-M529 (EP, 2005; see details in Medinas et al., 2013). The verges of these roads vary from 5 to $10 \mathrm{~m}$ wide and are vegetated with dense and tall grasses, different types of shrubs and scattered trees. When roads crosses woodland patches, the tree canopy covered most of the verges.

All transect routes were selected by their habitat homogeneity on both sides of the road within large, continuous habitat patches (of either woodland or open agricultural areas. Habitats were categorized as "woodland" when the tree canopy cover was above 30\%; otherwise, habitats were classified as "open agricultural field". Woodland areas provide high densities of insects and shelter from aerial predators (Rainho et al., 2010; Zimmerman and Glanz, 2000). These resources are much less available in open field areas, which makes them less suitable for bats. We surveyed bat activity up to $1000 \mathrm{~m}$ from the roads because we expected that the road-effect zone would be smaller in lowmedium traffic roads, compared to what has been reported for motorways (1600 m road-effect zone - Berthinussen and Altringham, 2012). Moreover, this was the maximum transect length available in the homogeneous habitat patches across the study area. Half of the transects were located in woodland areas (EN-114: 3 transects; EN-4: 4 transects and EN370-M529: 3 transects), and the other half were located in open agricultural field areas (EN-114: 4 transects; EN-4: 3 transects and EN370-M529: 3 transects).
To minimize the effects of other landscape variables, we selected patches that were at least $500 \mathrm{~m}$ away from water bodies, human settlements or other roads. The road sections that were studied were predominantly unlit, except on a few crossings and small settlements areas, and all of the transects were conducted along unlit sections. Air temperature, wind speed and percentage of cloud cover were recorded at the road, both before and after each night-period survey, by using a digital anemometer/thermometer (WS9500 Pocket Anemometer, La Crosse Technology, USA).

\subsection{Bat surveys and calls identification}

Bat surveys took place on one transect per night ( 6 point-locations that were simultaneously sampled at increasing distances from the road - Fig. 1), and each transect was surveyed three times between May and October of 2015, with a minimum of five weeks between the sampling sessions. Bat monitoring was performed on dry, warm and calm nights (minimum temperature $>13{ }^{\circ} \mathrm{C}$; wind speed $<3.5 \mathrm{~m} / \mathrm{s}$ ). Each survey started $30 \mathrm{~min}$ before sunset, in order to allow for varying emergence times of the different bat species, and ended $180 \mathrm{~min}$ after sunset, in order to comprise the peak of bat activity (Amorim et al., 2018). We used bat detectors (Petterson D500x, Petterson Elektronik $\mathrm{AB}$, Sweden) to passively detect, record and store full-spectrum bat echolocation call sequences (Ahlén and Baagøe, 1999). Bat detectors were set up on a tripod approximately $1.5 \mathrm{~m}$ above the ground and facing the road. Each detector was rotated between different distances to the road, in order to reduce the potential microphone sensitivity bias. Each detector's microphone was positioned at a $45^{\circ}$ angle relative to 
the ground and oriented towards the tree canopy gaps, in order to increase the number and quality of ultrasound recordings.

The bat call sequences were batch-processed by using the software Kaleidoscope (Wildlife Acoustics, Inc., version 3.1.1) through scrubbing (default settings), in order to remove noise recordings or low-intensity bat calls. We measured the bat calls that remained after the postscrubbing by using a custom $R$ script based on the seewave package (Sueur et al., 2008). A bat pass was defined as a search-phase echolocation sequence of at least 3 consecutive echolocation call pulses of one individual bat (Fenton, 2004), with the pass separated from the next pass by at least $1 \mathrm{~s}$. Bat calls were analysed by measuring parameters such as maximum energy frequency (FMaxE), pulse duration (D), inter-pulse interval (IPI), pulse initial (Fi) and final frequency (Fe). The frequency parameters (FMaxE, Fi and Fe) were measured from the power spectra of the entire call and were computed with the Fast Fourier Transform, whereas the time-related variables (IPI and D) were measured from the oscillograms. After obtaining the parameters, bat calls were identified to the species level or assigned to species complexes by using dichotomous keys for Portugal and for the Iberian Peninsula (Lisón, 2011; Rainho et al., 2013). Due to the high degree of overlap of the echolocation call characteristics, some species were identified to the genus level (e.g., Eptesicus: E. serotinus + E. isabellinus; Plecotus: P. auritus + P. austriacus). Species of the Myotis genus (most likely Myotis daubentonni, M. escalerai or $M$. myotis) were included in the same phonic group, and three Nyctalus species (N. noctula, N. lasiopterus and $N$. leisleri) were considered together. Other cases included the distinction between calls belonging to the Pipistrellus genus (mainly P. pygmaeus) and to Miniopterus schreibersii, whose echolocation calls are very similar. Thus, we opted for creating a composite category Pipistrellus spp./M. schreibersii.

To assess the influence of roads in the species with different traits, we grouped bats into guilds that reflected their echolocation ranges and clutter avoidances, namely, short-range echolocators (SRE; Myotis spp., Plecotus spp. and Rhinolophus spp.), mid-range echolocators (MRE; Pipistrellus spp. and M. schreibersii) and long-range echolocators (LRE; Eptesicus spp., Nyctalus spp. and Tadarida teniotis) (see details in Frey-Ehrenbold et al., 2013). As P. kuhlii comprises 57\% of the MRE guild passes, we excluded this species from the guild and bat overall community, and analysed its activity pattern separately.

\subsection{Statistical analysis}

We investigated the influence of distance to road on bat activity by using general linear mixed models (GLMM). However, because this relationship can be strongly modulated by habitat types for bat foraging, we also included the types of habitat (woodland or open agricultural field areas) as an explanatory variable in our models. Each transect and sampling session was included in the models as a random factor, in order to account for spatial and seasonal variation on bat activity, respectively. Additionally, to account for the spatial structure of the sampling point-locations along the same transect, we included an exponential correlation model that was developed with the coordinates of the point-locations (corExp) (Zuur et al., 2009). The number of overall community bat passes, the bat recordings of each guild and activity of $P$. kuhlii were log-transformed (count +1 ), in order to account for the occurrence of zero bat passes and to minimize the effect of possible outliers. We used the Gaussian with error distribution as an identity link function to test the effects of roads on bat activity.

Prior to the statistical analyses, the explanatory variables with skewed structures were transformed, in order to approach normality and to reduce the influence of extreme values (Zuur et al., 2009). The explanatory variables were then standardized to zero mean and unit variances, in order to allow for the comparison of their effect strengths (Burnham and Anderson, 2002). Collinearity among the explanatory variables was investigated by using pairwise correlations. For correlations that were higher than 0.7 , only the most biologically meaningful variables were retained for further analysis (Dormann et al., 2013). We also did a preliminary inspection of the variation of bat activity across the traffic categories: however, we did not find significant differences $(p>0.1)$. Thus, we pooled the bat activity data from all of the roads (Fig. A.1). Consequently, the explanatory variables that were used in the models were distance to the road and habitat type. The latter was included as a categorical variable, and the open agricultural areas were used as reference value. The distance to the roads was tested for both the linear and quadratic responses. All of the candidate models were built based on all of the possible subsets of the explanatory variables, including the null and the full models, as well as the interactions between the explanatory variables. The full models were structured in the following way:

\section{Bat activity $\sim$ Distance to road + Distance to road ${ }^{2}+$ Habitat type + Interaction terms, random \\ $=1 \mid$ Sampling session/Transect, structural correlation $=$ corExp (Easting + Northing $)$}

We used the Akaike Information Criterion, adjusted for small sample sizes (AICc), and the corresponding Akaike weights (wi), to rank the candidate models and to select the most parsimonious model for each case (Burnham and Anderson, 2002). The residual plots of residuals were examined, in order to check for normality, and deviance tests were performed, in order to assess the goodness of fit of the final models.

All analyses were performed in R version 3.3.2 ( $\mathrm{R}$ Development Core Team, 2006) by using the packages "nlme" (Pinheiro et al., 2007) and 'MuMIn' (Barton, 2013).

\subsection{Road-effect zone - identification of thresholds}

Whenever we detected a non-linear pattern in the relationship between bat activity and the distance to the road, we further investigated the presence of the breakpoints by using a piecewise regression to describe this relationship. This method allows for the identification of a threshold distance for the effect of roads on bat activity. We fitted the piecewise regression models to the transformed polynomial of the explanatory variable distance to the road by using the package "segmented" in R (Muggeo, 2015). We assessed the breakpoint value and its 95\% confidence interval for each habitat type (Toms and Lesperance, 2003). The breakpoint validation was performed by using the Davies' test, which compares the regression slopes before and after each breakpoint (Muggeo, 2015).

\section{Results}

A total of 29,239 bat passes were recorded from 360 detector-nights (20 transects $\times 6$ locations $\times 3$ nights), which corresponded to over 1080 survey hours. Of these, 24,455 (83.6\%) passes could be identified to the species level, while 4158 (14.2\%) were assigned to a singlegenus complex, $262(0.1 \%)$ were classified as a multi-genus complex and $364(0.1 \%)$ could not be identified (Table A.1).

Bat passes corresponded to eight genera, namely Pipistrellus $(N=$ $23,853 ; 82.6 \%)$, Eptesicus ( $N=984 ; 3.4 \%)$, Myotis $(N=698 ; 2.4 \%)$, Nyctalus $(N=2386 ; 8.3 \%)$, Barbastella $(N=189 ;<0.1 \%)$, Plecotus $(N$ $=85 ;<0.1 \%)$, Rhinolophus $(N=5 ;<0.1 \%)$, and Tadarida $(N=412$; 1.4\%) (Table A.1).

The detected activity of the three acoustic guilds was uneven; MRE had much higher activity $(N=24,115 ; 83.5 \%)$ than LRE $(N=3782$; $13.1 \%)$ and SRE $(N=977 ; 3.4 \%)$. Among the MRE, the species $P$. kuhlii accounted for $>50 \%$ of the guild's activity ( $N=13,789,57.2 \%)$; thus, this species was analysed separately. 


\subsection{Factors affecting bat activity and guild activity}

The activity of the bat community and of each species/group was markedly higher in the woodlands than in the open agricultural areas (Table A.2). In fact, the overall bat activity in the woodland sites was more than three times higher, compared with the open agricultural sites (passes per night: woodland, $810 \pm 93$; open agricultural areas, $234 \pm 34)$.

The best models for overall bat activity, the activity of the three bat guilds (SRE, MRE and LRE) and of P. kuhlii explained between 28.6 and $60.9 \%$ of the total variance. The most parsimonious models included habitat types, thus confirming that the activity of all of the groups and species tested were significantly higher in the woodlands than in the open agricultural areas (Table 1 and Table A.3). Three models - overall bat activity, SRE and MRE activity - yielded similar outputs and included the interaction between the distance to the road and habitat type, thus suggesting that the effect of roads on bat activity is different according to the two habitats that were tested. In the woodland areas, the activity of each of these groups slightly increased until intermediate distances from the road, after which they were approximately constant after that. This pattern was particularly pronounced in the SRE and MRE guilds. Conversely, in the open agricultural field areas, the activity of each of these groups of bats was lower at intermediate distances from the road and peaked at the shortest and largest distances (Table A.2).

The activity of the LRE bats and $P$. kuhlii was only affected by habitat type. Both bat groups were more active in the woodland areas, which was similar to the other bat groups that were analysed (Table 1 ).

\subsection{Estimated road-effect zone}

In the woodlands, the activity of the overall bats, of SRE and of MRE increased until an estimated distance of $310 \mathrm{~m}$ (SE = 270-349), $177 \mathrm{~m}$ ( $\mathrm{SE}=122-232)$ and $230 \mathrm{~m}$ (SE $=213-248)$, respectively, and remained high and approximately stable for larger distances (Fig. 2). When regarding the open agricultural areas, the pattern was different, with a decrease in activity at approximately $300 \mathrm{~m}$ from the road for each of these three bat groups, and a higher activity at the maximum distance of $1000 \mathrm{~m}$. For these bat groups and for both habitat types, the slopes of each of the two regression lines differed significantly ( $p<$ 0.001 ), thus supporting the existence of a breakpoint. For the LRE guild and for $P$. kuhlii, no breakpoints and no significant effects of distance to road were identified.

\section{Discussion}

\subsection{Habitat effects}

We found that there is a strong association between bat activity in the vicinity of roads and habitat type. For the bat guilds and species that was individually analysed, bat activity was much higher in the woodlands. This is consistent with the well-documented high importance of this habitat for European bat species, both as foraging (e.g., Davidson-Watts et al., 2006; Russ and Montgomery, 2002; Vaughan et al., 1997) and roosting areas (e.g., Boughey et al., 2011; Dietz et al., 2009; Russo and Jones, 2003). Food resources and roosts are much less available in open fields, which combine with low predator protection makes these areas less suitable for bats.

\subsection{Impact of roads on bat activity pattern}

The negative effects of high-traffic roads on bat activity are widely documented (e.g., Berthinussen and Altringham, 2012; Kitzes and Merenlender, 2014). According to Berthinussen and Altringham (2012), the avoidance of the vicinities of motorways by bats could be a response to the physical properties of large roads, such as wide gaps in the tree canopy, greater crossing distances (Fensome and Mathews, 2016) and high noise levels (Schaub et al., 2008). However, previous data on the impacts of low-medium traffic roads are scarce. We assessed the effects of the distance to these roads on bat activity, especially when considering the road-surrounding habitats. We found that the relationship between bat activity and the distance to the roads is non-linear and highly dependent on the surrounding habitats. Similarly, Berthinussen and Altringham (2012) found that favourable habitats that are crossed by roads had a comparably stronger increase in bat species richness than in degraded habitats. Our results also show that, when roads cross Mediterranean woodlands, which is a habitat rich in feeding and shelter resources for bats, they tend to avoid the immediate proximity of roads. This is in accordance with expectations because SRE bats Myotis spp. and Plecotus spp. - consistently select woodland areas while commuting, thus avoiding movement along road edges with lower tree cover than the adjacent habitats (Fensome and Mathews, 2016). In contrast, in the open agricultural areas, where resources are scarcer, we found that bat activity near the roads is similar to the activity that is registered $1000 \mathrm{~m}$ away from this infrastructure but is reduced at intermediate distances. These results suggest that, in habitats with fewer resources, road vicinity (i.e., road verges) may be a valuable habitat, likely for feeding, as has been documented for other mammals (de Redon et al., 2015) and birds (Laursen, 1981). Furthermore, the roadsides in intensive agriculture landscape may have acted as habitat edges or corridor-like habitats, due to the higher structural complexity of vegetation, when compared with landscape-matrix at intermediate distances from the road (Bernes et al., 2017).

The pattern herein described is compatible with the hypothesis that bat activity in road-surrounding areas is determined by a compromise between road avoidance, due to disturbance, and the use of resources provided by roads, which may be relevant when these resources are limited in the adjacent habitats. Moreover, we found that this pattern describes overall, SRE and MRE bat activity, but is not universal, as no significant road distance effect was detected for LRE (i.e., Nyctalus spp., Eptesicus spp. and T. teniotis) (Fig. A.2) or for P. kuhlii bats, which are the most common bat species in the study area. SRE and MRE guilds include the smaller bat species, and these species are likely the most prone to the deleterious effects of roads (Fensome and Mathews, 2016). Kerth and Melber (2009) found strong effects of a major road

Table 1

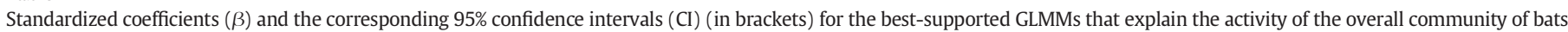

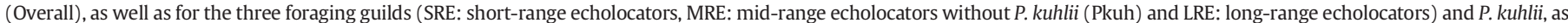

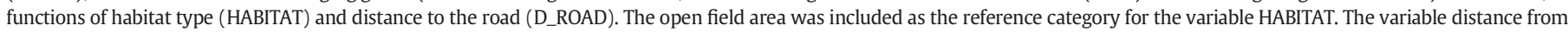
$\operatorname{road}(\mathrm{m})$ (D_ROAD) in quadratic form is identified with "^2". Highlighted in bold are parameters (except for the intercept) with CIs confidence intervals excluding zero.

\begin{tabular}{|c|c|c|c|c|c|c|c|c|c|c|}
\hline \multirow[t]{2}{*}{ Variable } & \multicolumn{2}{|l|}{ Overall } & \multicolumn{2}{|l|}{ SRE } & \multicolumn{2}{|l|}{ MRE } & \multicolumn{2}{|l|}{ LRE } & \multicolumn{2}{|l|}{ Pkuh } \\
\hline & $\beta$ & $C I$ & $\beta$ & $C I$ & $\beta$ & $C I$ & $\beta$ & $C I$ & $\beta$ & $C I$ \\
\hline HABITAT & 1.406 & $(1.021 ; 1.791)$ & 0.402 & $(0.155 ; 0.649)$ & 1.430 & $(0.971 ; 1.890)$ & 1.063 & $(0.742 ; 1.384)$ & 1.360 & $(0.863 ; 1.856)$ \\
\hline D_ROAD & 1.768 & $(-0.644 ; 4.180)$ & 1.118 & $(-0.948 ; 3.315)$ & 2.239 & $(-0.527 ; 5.184)$ & - & - & - & - \\
\hline D_ROAD^2 & 5.025 & $(2.666 ; 7.384)$ & 2.066 & $(0.002 ; 4.110)$ & 4.176 & $(1.396 ; 6.956)$ & - & - & - & - \\
\hline D_ROAD*HABITAT & 1.064 & $(-2.161 ; 4.291)$ & 0.954 & $(-1.899 ; 3.807)$ & 1.456 & $(-2.364 ; 5.275)$ & - & - & - & - \\
\hline D_ROAD^2*HABITAT & -5.673 & $(-8.836 ;-2.510)$ & -2.871 & $(-5.610 ;-0.131)$ & -6.391 & $(-10.117 ;-2.664)$ & - & - & - & - \\
\hline Intercept & 2.464 & $(2.183 ; 2.745)$ & 0.657 & $(0.473 ; 0.842)$ & 1.934 & $(1.599 ; 2.270)$ & 1.263 & $(1.029 ; 1.500)$ & 1.879 & $(1.280 ; 2.478)$ \\
\hline
\end{tabular}



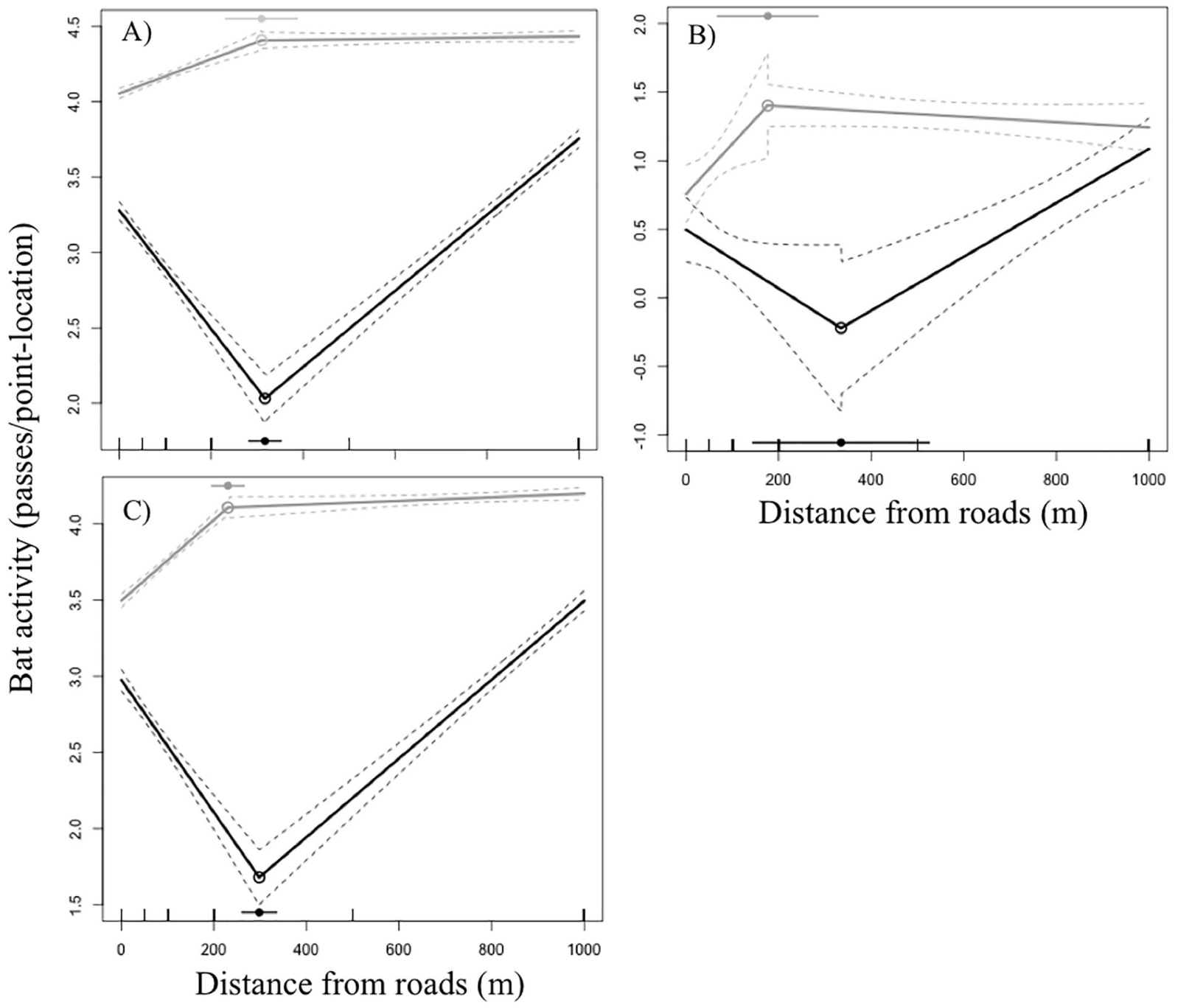

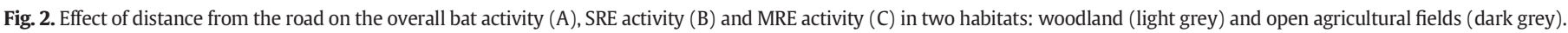
Solid lines show the best fit piecewise regression models with $95 \%$ CIs (dashed lines). Filled circles indicate breakpoints in the relationship and associated standard errors.

on habitat use for the SRE species Myotis bechsteinii. Likewise, the activity of $P$. pipistrellus, an MRE bat, was also lower in proximity to a major road (Berthinussen and Altringham, 2012). These results, together with ours, suggest that gleaning, edge and forest dwelling species, which forage in cluttered habitats, can be more susceptible to negative impacts from roads.

On the other hand, LRE bats, which usually fly high and fast above the tree canopy while feeding in open spaces (Jensen and Miller, 1999; Marques et al., 2004), should be less affected by road disturbance (Jung and Kalko, 2011; Russo and Ancillotto, 2015), and may depend less on possible resources that are provided by roads (Fig. A.2). This is supported by empirical data showing that this bat guild registered very low numbers of road kills (Fensome and Mathews, 2016; Medinas et al., 2013). P. kuhlii is a synanthropic and generalist species that is able to forage in a wide range of habitats (Carmel and Safriel, 1998; Dietz et al., 2009; Georgiakakis et al., 2010; Lisón and Calvo, 2013; Rainho, 2007), including over lit and unlit road edges (Kahnonitch et al., 2018). In addition, it can roost in buildings and tree holes (Cruz et al., 2016) that can be located on road verges (DM, personal observation).

\subsection{Spatial extent of road-effect zone}

We evaluated road distance effects up to $1000 \mathrm{~m}$ from roads, and we found an influence on overall bat activity up to approximately $300 \mathrm{~m}$ for both habitats. This is slightly shorter for the SRE (170 m) and MRE $(230 \mathrm{~m})$ guilds in roads that cross woodlands, when compared with open field areas (SRE - $330 \mathrm{~m}$; MRE - $300 \mathrm{~m}$ ), thus suggesting that tree cover may partly buffer the negative effects of roads on surrounding areas. Other studies have shown that negative effects of roads on bats can extend to greater distances; for example, Berthinussen and Altringham (2012) reported effects at distances up to $1600 \mathrm{~m}$ from a large motorway in the UK. However, those studies were performed in much larger roads with high traffic volumes that were at least six-fold higher than the registered volumes in our area, thus suggesting that traffic, road characteristics or habitat contexts need to be taken into account, in order to properly characterize the road-effect zone.

\subsection{Implications for roadside management}

This study highlights that low-medium traffic roads should be considered as a major pressure on global bat conservation, because almost $50 \%$ of the worldwide transport infrastructure is accounted for in this traffic category (Meijer et al., 2018). Our study also shows a relatively higher bat activity for the immediate vicinity of roads when these roads cross open fields, thus suggesting that the preservation of vegetation along roads, such as strips of tall grass, shrubs and, whenever possible, treelines, may be important, in order to increase the suitability of roadsides for bats. The important role of verges as bat feeding areas has been previously reported for railways that cross intensive agricultural 
areas (Vandevelde et al., 2014). Moreover, when roads cross less suitable areas, roadsides may also act as dispersal corridors and may be the last landscape refuge for many small vertebrates and invertebrates (e.g., Forman and Alexander, 1998; Sabino-Marques and Mira, 2013; Trombulak and Frissell, 2000; Wynhoff et al., 2011), thus offering feeding opportunities for their predators.

Nevertheless, we need to be cautious when promoting wildlife habitat use near roads because we are also increasing the risk of collision with vehicles. Medinas et al. (2013) found that approximately 3 bats/ $\mathrm{km} /$ year are road killed on the same roads that were surveyed in our study. This is an unexpectedly large number of road kills whose impacts on the long-term viability of populations still need to be evaluated. Moreover, it is also known that the presence of trees and shrubs tends to increase the likelihood of bat road-crossing (Abbott et al., 2012; Bennett and Zurcher, 2013).

Thus, a better potential mitigation measure for reducing the effects of roads should be the creation of bat feeding habitats (e.g., planting insect friendly shrubs and trees, or creating ponds) away from roads (e.g., Wyatt, 2010; Berthinussen and Altringham, 2012; Berthinussen and Althringham, 2015). The recommended distance from high traffic roads to habitat improvements is $1000 \mathrm{~m}$; however according to our findings for low-medium traffic roads, we suggest that this distance should be approximately half of the previously reported distance. This new information will strengthen the road corridor planning and overall landscape management that aims to enhance bat conservation in roaddominated landscapes.

\section{Conclusion}

Our study provides the first insights into how low-medium traffic roads affect bat activity. Overall, the results emphasize that roadeffects on bats are non-linear and depend on the functional characteristics of the species and the road-habitat contexts. We highlighted that trade-offs that are posed by roads between feeding/commuting opportunities and road kill risk must be taken in account during road planning and in implementation of mitigation measures. This is a priority, and it represents a non-consensual and poorly addressed issue that needs to be disentangled.

We are aware that additional data (e.g. prey availability, noise, light and management of verges) are needed in order to properly understand the causes underlying of the patterns that we observed. However, our results underline that the road-surrounding habitat is a key component of this system. This study provides some important clues about the role of vegetation management in verges and surrounding areas, in order to keep road-dominated landscapes more suitable and safer for bats. Nevertheless, our results also raise key challenging questions in roadside wildlife management: (1) Are road-related habitats opportunities for bat (and other wildlife) conservation? (2) If yes, under what circumstances? These are two of the many questions that need to be considered in order to properly evaluate the pattern and intensity of road effects on wildlife and, to efficiently mitigate these effects.

Supplementary data to this article can be found online at https://doi. org/10.1016/j.scitotenv.2019.01.032.

\section{Acknowledgements}

We are indebted to all who kindly provided assistance during field work, and to SS for helpful suggestions on an earlier draft of the manuscript, SB for aiding with call identification. DM was financed by Fundação para a Ciência e Tecnologia (FCT) with doctoral grant SFRH/ BD/104861/2014. AMB and HR were supported by FCT and FEDER/ COMPETE 2020 through an "Investigador FCT" contract (IF/00266/ 2013 and IF/04313/2017, respectively) and AMB also supported by an exploratory project (CP1168/CT0001). This study was funded by the European Regional Development Fund (ERDF) through the COMPETE and National Funds through the FCT and European Commission, under the projects POPCONNECT-PTDC/AAG-MAA/0372/2014 and LIFE LINES-LIFE14-NAT-PT-001081, respectively.

\section{References}

Abbott, I.M., Butler, F., Harrison, S., 2012. When flyways meet highways - the relative permeability of different motorway crossing sites to functionally diverse bat species. Landsc. Urban Plan. 106, 293-302. https://doi.org/10.1016/j.landurbplan.2012.03.015.

Ahlén, I., Baagøe, H.J., 1999. Use of ultrasound detectors for bat studies in Europe: experiences from field identification, surveys, and monitoring. Acta Chiropterol. 1, 137-150

Amorim, F., Jorge, I., Beja, P., Rebelo, H., 2018. Following the water? Landscape-scale temporal changes in bat spatial distribution in relation to Mediterranean summer drought. Ecol. Evol. 8 (11), 5801-5814. https://doi.org/10.1002/ece3.4119.

Ascensão, F., Mata, C., Malo, J.E., Ruiz-Capillas, P., Silva, C., Silva, A.P., Santos-Reis, M., Fernandes, C., 2016. Disentangle the causes of the road barrier effect in small mammals through genetic patterns. PLoS One 11 (3), e0151500. https://doi.org/10.1371/ journal.pone.0151500

Balkenhol, N., Waits, L.P., 2009. Molecular road ecology: exploring the potential of genetics for investigating transportation impacts on wildlife. Mol. Ecol. 18 (20) 4151-4164. https://doi.org/10.1111/j.1365-294X.2009.04322.x.

Barton, K., 2013. MuMIn: Multi-model Inference. R Package Version 1.9.13. http://CRAN R-project.org/package =MuMIn https://doi.org/10.1007/s10531-008-9499-9.

Benítez-López, A., Alkemade, R., Verweij, P.A., 2010. The impacts of roads and other infrastructure on mammal and bird populations: a meta-analysis. Biol. Conserv. 143 1307-1316. https://doi.org/10.1016/j.biocon.2010.02.009.

Bennett, V.J., Zurcher, A., 2013. When corridors collide: road-related disturbance in commuting bats. J. Wildl. Manag. 77, 93-101. https://doi.org/10.1002/jwmg.467.

Bennett, V.J., Sparks, D.W., Zollner, P.A., 2013. Modelling the indirect effects of road networks on the foraging activities of bats. Landsc. Ecol. 28 (5), 979-991. https://doi org/10.1007/s10980-013-9874-0.

Bernes, C., Bullock, J., Jakobsson, S., Rundlof, M., Verheyen, K., Lindborg, R., 2017. How are biodiversity and dispersal of species affected by the management of roadsides? A systematic map protocol. Environ. Evid. 6, 1-7. https://doi.org/10.1186/s13750-0170103-1.

Berthinussen, A., Althringham, J., 2015. WC1060: Development of a Cost-effective Method for Monitoring the Effectiveness of Mitigation for Bats Crossing Linear Transport Infrastructure. Final Report to Defra.

Berthinussen, A., Altringham, J., 2012. The effect of a major road on bat activity and diversity. J. Appl. Ecol. 49, 82-89. https://doi.org/10.1111/j.1365-2664.2011.02068.x.

Boughey, K.L., Lake, I.R., Haysom, K.A., Dolman, P.M., 2011. Effects of landscape-scale broadleaved woodland configuration and extent on roost location for six bat species across the UK. Biol. Conserv. 144, 2300-2310. https://doi.org/10.1016/j. biocon.2011.06.008.

Burnham, K.P., Anderson, D.R., 2002. Model Selection and Multimodel Inference: A Practical Information-Theoretic Approach. 2nd ed. Springer-Verlag, New York, NY.

Carmel, Y., Safriel, U., 1998. Habitat use by bats in a Mediterranean ecosystem in Israel conservation implications. Biol. Conserv. 84, 245-250. https://doi.org/10.1016/ S0006-3207(97)00131-6.

Clevenger, A.P., Waltho, N., 2000. Factors influencing the effectiveness of wildlife underpasses in Banff National Park, Alberta, Canada. Conserv. Biol. 14, 47-56. https://doi org/10.1046/j.1523-1739.2000.00099-085.x.

Cruz, J., Sarmento, P., Rydevik, G., Rebelo, H., White, P.C.L., 2016. Bats like vintage: managing exotic eucalypt plantations for bat conservation in a Mediterranean landscape. Anim. Conserv. 19, 53-64. https://doi.org/10.1111/acv.12216.

Davidson-Watts, I., Walls, S., Jones, G., 2006. Differential habitat selection by Pipistrellus pipistrellus and Pipistrellus pygmaeus identifies distinct conservation needs for cryptic species of echolocating bats. Biol. Conserv. 133, 118-127. https://doi.org/10.1016/j. biocon.2006.05.027.

Davies, Z.G., Pullin, A.S., 2007. Are hedgerows effective corridors between fragments of woodland habitat? An evidence-based approach. Landsc. Ecol. 22, 333-351. https:// doi.org/10.1007/s10980-006-9064-4.

Dietz, C., von Helversen, O., Nill, D., 2009. Bats of Britain, Europe and Northwest Africa. 2nd ed. A\&C Black, London.

Dodd Jr., C.K., Barichivich, W.J., Smith, L.L., 2004. Effectiveness of a barrier wall and culverts in reducing wildlife mortality on a heavily traveled highway in Florida. Biol. Conserv. 118, 619-631. https://doi.org/10.1016/j.biocon.2003.10.011.

Dormann, C.F., Elith, J., Bacher, S., Buchmann, C., Carl, G., Carré, G., Marquéz, J.R.G., Gruber, B., Lafourcade, B., Leitão, P.J., Munkemuller, T., McClean, C., Osborne, P.E., Reineking B., Schroder, B., Skidmore, A.K., Zurell, D., Lautenbach, S., 2013. Collinearity: a review of methods to deal with it and a simulation study evaluating their performance. Ecography 36, 027-046. https://doi.org/10.1111/j.1600-0587.2012.07348.x.

EP, 2005. Recenseamento Do Tráfego - Évora. Estradas de Portugal, E.P.E.

Fahrig, L., Rytwinski, T., 2009. Effects of roads on animal abundance: an empirical review and synthesis. Ecol. Soc. 14 (1), 21. http://www.ecologyandsociety.org/vol14/iss1/ art21/.

Fensome, A.G., Mathews, F., 2016. Roads and bats: a meta-analysis and review of the evidence on vehicles collisions and barrier effects. Mammal Rev. 46, 311-323. https:// doi.org/10.1111/mam.12072.

Fenton, M.B., 2004. Reporting: essential information and analysis. In: Brigham, M., Kalko, E.K.V., Jones, G., Parsons, S., Limpens, H.J. (Eds.), Bat Echolocation Research: Tools, Techniques and Analysis. Bat Conservation International, Austin, pp. 133-140.

Forman, R.T., Alexander, L., 1998. Roads and their major ecological effects. Annu. Rev. Ecol. Syst. 29, 207-231.

Forman, R.T.T., Sperling, D., Bissonette, J., Clevenger, A.P., Cutshall, C.D., Dale, V.H., Fahrig L., France, R., Goldman, C., Heanue, K., Jones, J., Swanson, F., Turrentine, T., Winter, T., 
2003. Road Ecology: Science and Solutions. Island Press, Washington, District of Columbia.

Frey-Ehrenbold, A., Bontadina, F., Arlettaz, R., Obrist, M., 2013. Landscape connectivity, habitat structure and activity of bat guilds in farmland-dominated matrices. J. Appl. Ecol. 50, 252-261. https://doi.org/10.1111/1365-2664.12034.

Gaisler, J., Řehák, Z., Bartonička, T., 2009. Bat casualties by road traffic (Brno-Viena). Acta Theriol. 54, 147-155.

Galantinho, A., Eufrázio, S., Silva, C., Carvalho, F., Alpizar-Jara, R., Mira, A., 2017. Road ef fects on demographic traits of small mammal populations. Eur. J. Wildl. Res. 63 (1), 22. https://doi.org/10.1007/s10344-017-1076-7.

Georgiakakis, P., Vasilakopoulos, P., Mylonas, M., Russo, D., 2010. Bat species richness and activity over an elevation gradient in Mediterranean shrubland of Crete. Hystrix Ital. J. Mammal. 21 (1), 43-56. https://doi.org/10.4404/hystrix-21.1-4485.

Grilo, C., Sousa, J., Ascensão, F., Matos, H., Leitão, I., Pinheiro, P., Costa, M., Bernardo, J., Reto D., Lourenço, R., Santos-Reis, M., Revilla, E., 2012. Individual spatial responses towards roads: implications for mortality risk. PLoS One 7 (9), e43811. https://doi.org/ 10.1371/journal.pone.0043811.

Hale, J.D., Fairbrass, A.J., Matthews, F., Thomas, J., Davies, G., Sadler, J.P., 2015. The ecolog ical impact of city lighting scenarios: exploring gap crossing thresholds for urban bats. Glob. Chang. Biol. 21 (7), 2467-2478. https://doi.org/10.1111/gcb.12884.

Jackson, N.D., Fahrig, L., 2011. Relative effects of road mortality and decreased connectivity on population genetic diversity. Biol. Conserv. 144 (12), 3143-3148. https://doi. org/10.1016/j.biocon.2011.09.010.

Jaeger, J.A.G., Bowman, J., Brennan, J., Fahrig, L., Bert, D., Bouchard, J., Charbonneau, N. Frank, K., Gruber, B., Tluk, K., von Toschanowitz, T., 2005. Predicting when animal populations are at risk from roads: an interactive model of road avoidance behavior. Ecol. Model. 185, 329-348. https://doi.org/10.1016/j.ecolmodel.2004.12.015.

Jensen, M.E., Miller, L.A., 1999. Echolocation signals of the bat Eptesicus serotinus recorded using a vertical microphone array: effect of flight altitude on searching signals. Behav. Ecol. Sociobiol. 47, 60-69. https://doi.org/10.1007/s002650050650.

Jung, K., Kalko, E.K., 2011. Adaptability and vulnerability of high flying neotropical aerial insectivorous bats to urbanization. Biodivers. Res. 17, 262-274. https://doi.org/ 10.1111/j.1472-4642.2010.00738.x.

Kahnonitch, I., Lubin, Y., Korine, C., 2018. Insectivorous bats in semi-arid agroecosystems - effects on foraging activity and implications for insect pest control. Agric. Ecosyst. Environ. 261, 180-192. https://doi.org/10.1016/j.agee.2017.11.003.

Kerth, G., Melber, M., 2009. Species-specific barrier effects of a motorway on the habitat use of two threatened forest-living bat species. Biol. Conserv. 142, 270-279. https:// doi.org/10.1016/j.biocon.2008.10.022.

Kitzes, J., Merenlender, A., 2014. Large roads reduce bat activity across multiple species. PLoS One 9, e96341. https://doi.org/10.1371/journal.pone.0105388.

Laursen, K., 1981. Birds on roadsides verges and the effect of mowing on frequency and distribution. Biol. Conserv. 20 (1), 59-68. https://doi.org/10.1016/0006-3207(81) 90061-6.

Lesiński, G., 2007. Bat road casualties and factors determining their number. Mammalia 71, 138-142. https://doi.org/10.1515/MAMM.2007.020.

Lesiński, G., Sikora, A., Olszewski, A., 2010. Bat casualties on a road crossing a mosaic landscape. Eur. J. Wildl. Res. 57 (2), 217-223. https://doi.org/10.1007/s10344-010-04149.

Lisón, F., 2011. Clave de identificación de las llamadas de ecolocación de los murciélagos de la Penıínsula Ibérica. Versión electrónica 1.0. http://quiromur.blogspot.com/p/ publicaciones.html (Accessed Oct 2015).

Lisón, F., Calvo, J.F., 2013. Ecological niche modelling of three pipistrelle bat species in semiarid Mediterranean landscapes. Acta Oecol. 47, 68-73. https://doi.org/10.1016/ j.actao.2013.01.002.

Luo, J., Siemers, B.M., Koselj, K., 2015. How anthropogenic noise affects foraging. Glob. Chang. Biol. 21, 3278-3289. https://doi.org/10.1111/gcb.12997.

Marques, J.T., Rainho, A., Carapuço, M., Oliveira, P., Palmeirim, J.M., 2004. Foraging behaviour and habitat use by the European free-tailed bat Tadarida teniotis. Act Chiropterol. 6 (1), 99-110. https://doi.org/10.3161/001.006.0108.

Medinas, D., Marques, J.T., Mira, A., 2013. Assessing road effects on bats: the role of landscape, road features and bat activity on roadkills. Ecol. Res. 28 (2), 227-237. https:// doi.org/10.1007/s11284-012-1009-6.

Meijer, J., Juijbregts, M., Schotten, K., Schipper, M., 2018. Global patterns of current and future road infrastructure. Environ. Res. Lett. 13, 064006. https://doi.org/10.1088/17489326/aabd42

Muggeo, V.M.R., 2015. 'Segmented: Regression Models With Breakpoints Changepoints Estimation. R Package Version 0.5-1.1. Available at. http://CRAN.R project.org/package $=$ segmented.

O'Farrell, P.J., Milton, S.J., 2006. Road verge and rangeland plant communities in the southern Karoo: exploring what influences diversity, dominance and cover. Biodivers. Conserv. 15 (2), 921-938. https://doi.org/10.1007/s10531-004-3102-9.

Penone, C., Machon, N., Julliard, R., Le Viol, I., 2012. Do railway edges provide functional connectivity for plant communities in an urban context? Biol. Conserv. 148 (1) 26-133. https://doi.org/10.1016/j.biocon.2012.01.041.

Pinheiro, J.C., Bates, D.M., DebRoy, S., Sarkar, D., 2007. NLME: Linear and Nonlinear Mixed Effects Models. R Package Version 3.1-83. Available at. http://CRAN.R project.org/ package $=$ nlme.

R Development Core Team, 2006. R: A Language and Environment for Statistical Computing. R Foundation for Statistical Computing, Vienna Available at. http://www.R-project.org.

Rainho, A., 2007. Summer foraging habitats of bats in a Mediterranean region of the Iberian Peninsula. Acta Chiropterol. 9, 171-181. https://doi.org/10.3161/1733-5329.

Rainho, A., Augusto, A.M., Palmeirim, J.M., 2010. Influence of vegetation clutter on the capacity of ground foraging bats to capture prey. J. Appl. Ecol. 47, 850-858. https://doi. org/10.1111/j.1365-2664.2010.01820.x.
Rainho, A., Alves, P., Amorim, F., Marques, J.T., 2013. Atlas dos morcegos de Portugal continental. Instituto da Conservação da Natureza e das Florestas, Lisbon.

de Redon, L., Le Viol, I., Jiguet, F., Machon, N., Scher, O., Kerbiriou, C., 2015. Road network in an agrarian landscape: potential habitat, corridor or barrier for small mammals? Acta Oecol. 62, 58-65. https://doi.org/10.1016/j.actao.2014.12.003.

Reed, D.H., Nicholas, C., Stratton, G.E., 2007. Genetic quality of individuals impacts population dynamics. Anim. Conserv. 10, 275-283. https://doi.org/10.1111/j.14691795.2007.00120.x

Rotholz, E., Mandelik, Y., 2013. Roadside habitats: effects on diversity and composition of plant, arthropod, and small mammal communities. Biodivers. Conserv. 22, 1017-1031. https://doi.org/10.1007/s10531-013-0465-9.

Russ, J.M., Montgomery, W.I., 2002. Habitat associations of bats in Northern Ireland: implications for conservation. Biol. Conserv. 108, 49-58. https://doi.org/10.1016/ S0006-3207(02)00089-7.

Russell, A., Butchkoski, C., Saidak, L., McCracken, G., 2009. Road-killed bats, highway design, and the commuting ecology of bats. Endanger. Species Res. 8, 49-60. https:// doi.org/10.3354/esr00121

Russo, D., Ancillotto, L., 2015. Sensitivity of bats to urbanization: a review. Mammalian Biology-Zeitschrift für Säugetierkunde. 80 (3), 205-212. https://doi.org/10.1016/j. mambio.2014.10.003.

Russo, D., Jones, G., 2003. Use of foraging habitats by bats in a Mediterranean area determined by acoustic surveys: conservation implications. Ecography 26, 197-209. https://doi.org/10.1034/j.1600-0587.2003.03422.x.

Rytwinski, T., Fahrig, L., 2013. Why are some animal populations unaffected or positively affected by roads? Oecologia 173, 1143-1156. https://doi.org/10.1007/s00442-0132684-x

Sabino-Marques, H., Mira, A., 2013. Living on the verge: are roads a more suitable refuge for small mammals than streams in Mediterranean pastureland? Ecol. Res. 26 (2), 277-287. https://doi.org/10.1007/s11284-010-0781-4.

Santos, R.A.L., Santos, S.M., Santos-Reis, M., De Figueiredo, A.P., Bager, A., Aguiar, L.M.S., Ascensão, F., 2016. Carcass persistence and detectability: reducing the uncertainty surrounding wildlife-vehicle collision surveys. PLoS One 11, 1-15. https://doi.org/ 10.1371/journal.pone.0165608.

Schaub, A., Ostwald, J., Siemers, B.M., 2008. Foraging bats avoid noise. J. Exp. Biol. 211, 3174-3180. https://doi.org/10.1242/jeb.022863.

Secco, H., Augusto Gomes, L., Lemos, H., Mayer, F., Machado, T., Guerreiro, M., Gregorin, R. 2017. Road and landscape features that affect bat roadkills in southeastern Brazil. Oecol. Aust. 21, 323-336. https://doi.org/10.4257/oeco.2017.2103.09.

Siemers, B.M., Schaub, A., 2011. Hunting at the highway: traffic noise reduces foraging efficiency in acoustic predators. P. R. Soc. B Biol. Sci. 278, 1646-1652. https://doi.org/ $10.1098 /$ rspb.2010.2262

Stone, E.L., Jones, G., Harris, S., 2009. Street lighting disturbs commuting bats. Curr. Biol. 19, 1123-1127. https://doi.org/10.1016/j.cub.2009.05.058.

Stone, E.L., Jones, G., Harris, S., 2012. Conserving energy at a cost of biodiversity? Impacts of LED lighting on bats. Glob. Chang. Biol. 18, 2458-2465. https://doi.org/10.1111/ j.1365-2486.2012.02705.x

Sueur, J., Aubin, T., Simonis, C., 2008. Seewave: a free modular tool for sound analysis and synthesis. Bioacoustics 18, 213-226. https://doi.org/10.1080/ 09524622.2008.9753600.

Toms, J.D., Lesperance, M.L., 2003. Piecewise regression: a tool for identifying ecological thresholds. Ecology 84, 2034-2041. https://doi.org/10.1890/02-0472.

Torres, A., Jaeger, J.A.G., Alonso, J.C., 2016. Assessing large-scale wildlife responses to human infrastructure development. Proc. Natl. Acad. Sci. 113, 8472-8477. https:// doi.org/10.1073/pnas.1522488113.

Trombulak, S.C., Frissell, C., 2000. Review of ecological effects of roads on terrestrial and aquatic communities and of aquatic ecological effects of roads on terrestrial communities. Conserv. Biol. 14, 18-30. https://doi.org/10.1046/j.1523-1739.2000.99084.x.

Vandevelde, J.C., Bouhours, A., Julien, J.F., Couvet, D., Kerbiriou, C., 2014. Activity of European common bats along railway verges. Ecol. Eng. 64, 49-56. https://doi.org/ 10.1016/j.ecoleng.2013.12.025.

Vaughan, N., Jones, G., Harris, S., 1997. Habitat use by bats (Chiroptera) assessed by means of a broad-band acoustic method. J. Appl. Ecol. 34, 716-730. https://www.jstor.org/ stable/2404918.

Westemeier, R.L., 1998. Tracking the long-term decline and recovery of an isolated population. Science 282, 1695-1698. https://doi.org/10.1126/science.282.5394.1695.

Wyatt, L., 2010. Experiences of Dealing with Lesser Horseshoe Bats (Rhinolophus hipposideros / Kleine Hufeisennase) in Wales, United Kingdom. Presentation held at "Berücksightigung von Fledermäusen bei der Strasssenplaning. 24th June 2010 in Cologne, Germany.

Wynhoff, I., van Gestel, R., van Swaay, C., van Langevelde, F., 2011. Not only the butterflies: managing ants on road verges to benefit Phengaris (Maculinea) butterflies. J. Insect Conserv. 15, 189-206. https://doi.org/10.1007/s10841-010-9337-8.

Yanes, M., Velasco, J.M., Suárez, F., 1995. Permeability of roads and railways to vertebrate: the importance of culverts. Biol. Conserv. 71, 217-222. https://doi.org/10.1016/00063207(94)00028-0.

Zimmerman, G.S., Glanz, W.E., 2000. Habitat use by bats in eastern Maine. J. Wildl. Manag. 64, 1032-1040. https://www.jstor.org/stable/3803214.

Zurcher, A.A., Sparks, D.W., Bennett, V.J., 2010. Why the bat did not cross the road? Acta Chiropterol. 12 (2), 337-340. https://doi.org/10.3161/150811010X537918.

Zuur, A.F., Ieno, E.N., Walker, N.J., Saveliev, A.A., Smith, G.M., 2009. Mixed Effects Models and Extensions in Ecology with R. Springer, New York, London. 